\title{
Characterization of students formal-proof construction in mathematics learning
}

\author{
Syamsuri $^{\mathrm{a}, *}$, Purwanto $^{\mathrm{b}}$, Subanji $^{\mathrm{b}}$, Santi Irawati ${ }^{\mathrm{b}}$ \\ ${ }^{a}$ Universitas Sultan Ageng Tirtayasa, Jl Raya Jakarta KM 4 Pakupatan, Serang 421 18, Indonesia \\ ${ }^{b}$ Universitas Negeri Malang, Jl Semarang 5, Malang 65145, Indonesia
}

Article history:

Received: 19 April 2016 / Received in revised form: 16 November 2016 / Accepted: 18 November 2016

\begin{abstract}
Formal proof is a deductive process beginning from some explicitly quantified definitions and other mathematical properties to get a conclusion. Characteristics of student formal-proof construction are required to identify the appropriate treatment can be determined. The purpose of this study was to describe the characteristics of the construction of formal-proof based overview of the proof structure and conceptual understanding that the student possessed. The data used in this article were obtained from the 3-step processes: students are asked to write down the proof of proving-question, they are asked about the knowledge required in constructing proof using questionnaire, and then they are interviewed. The results showed that formal-proof construction could be modeled by the Quadrant-Model. First Quadrant describes correct construction of formal-proof, Second Quadrant describes insufficiencies concept in construction formal-proof, Third Quadrant indicates insufficiencies concept and proof-structure in construction formal-proof and Fourth Quadrant describes incorrect proof-structure in construction of formal-proof. This model could give consideration on how to help students who are in Quadrant II, III, and IV to be able to construct a formal proof like Quadrant I.
\end{abstract}

Keywords: Mathematics Learning; Proof Construction; Formal-proof; Quadrant-Model

\section{Introduction}

Proof and proving in mathematics education are an important part of mathematics, as a pillar of the mathematics building. Therefore, mathematics education especially in mathematics learning in university emphasizes the constructing of mathematical proof. Students who enter college level should develop a formal mathematical knowledge. Formal proof refers to a form of an accurate logic as described by Hilbert, or refers to a form of proof used by mathematicians to communicate with each other in seminars or scientific article [1]. Mathematical proof of students needs to be trained so that they can understand the formal mathematical structure.

Students are introduced to formal proof in the study of mathematics at university. Formal proof as a process begins from explicit quantified definitions and deduces that other properties hold as a consequence [2]. Learning how to construct formal proof is given to make sense a formal definition that can be used in building the basis of deduction theorem.

The previous study has revealed that most students have difficulty in constructing a mathematical proof [3-6]. Moore [3] reveals that there are 7 difficulties experienced by students in constructing the proof, namely: (1) students did not know

* Corresponding author. Tel.: +62-813-8961-3991 ; fax: +62-254-281-254 Email:syamsuri@untirta.ac.id. the definition, (2) students have little intuitive understanding of the concept, (3) concept image of students were inadequate for doing the proofs, (4) students are unable to generate and use their own example, (5) students did not know how to use definition, (6) students have difficulties in using mathematical language and notation, and (7) students did not know how to begin proofs. Knapp [4] argues that what Moore stated is the difficulty as sociated with understanding the concept, and not in deductive logic in constructing proofs. Therefore, Knapp [4] categorizes students in constructing proofs into: (1) difficulties in how to use logic and language of proof, (2) lack of specific knowledge of definition, theorem, heuristics and ability to generate example.

In the process of constructing proofs, Pinto and Tall [7] used the term 'natural' to describe the process of extracting meaning and the term 'formal' to the process of giving meaning that work formally. In addition to the term 'natural' and 'formal', Weber [8] adds the notion of learning 'procedural' for students who are just trying to cope with formal definitions and proof with rote learning. Alcock and Weber [9] customize the student's response to 'semantic' and 'syntactic' 'with base terms in language which refers to the meaning of semantic contents and syntax. Alcock and Weber describe syntactic approach as one of the strategies in mathematical proofs by working from a literal reading of the definitions involved and semantic approach as a strategy in utilizing the intuitive understanding of a concept. It is in line 
with the term of extracting meaning and giving meaning in the category of 'formal' and 'natural'.

Moore [3] stated that there are two sequences used by the students in constructing proofs, namely: (1) Concept Image $\rightarrow$ Concept Definition $\rightarrow$ Concept Usage, and (2) Concept Image $\rightarrow$ Concept Usage. Concept Image (CI) is the individual's general intuitive understanding of a concept. CI associated images and ideas. Concept Definition (CD) is the individual's definition for the concept. CD may be fairly disconnected from the concept image [10]. Concept-image is a picture of students' cognitive schema of the concepts that are given, concept-definition is a mathematical concept denoted in the formal form, while concept-usage is a concept used by the student in constructing proofs. The first step indicates that the student is able to construct a formal proof properly, while the second step indicates that the student has not been able to construct formal. According to Pinto and Tall's framework [7], the first step is identical to formal, while the second step is identical to natural.

In the theory of information processing, mathematical proof process must always involve human cognitive architecture. Sweller [11] states that human cognitive architecture is defined as a way of organizing the structure and functions required in the human cognitive processes. Cognitive structure consists of working memory and long term memory [12]. Working memory is where information processing, whereas long-term memory is where it keeps information in the form of schemata [13]. The scheme is in charge of managing the cognitive construction elements of information in long-term memory. All the knowledge acquired by a person stored in the form of a scheme managed in units. Scheme is a system in charge of the human mind to understand the knowledge, presenting knowledge, and use that knowledge. Therefore, the scheme contains all the information and relationships of a concept.

The importance of the human scheme is that a concept scheme evolves with experience and new knowledge. This means that the human scheme is a dynamic thing that may change from time to time depending on experience and new information. Scheme managed through assimilation and accommodation. Assimilation is the process of interpreting the new knowledge and experiences with existing schemes, while the accommodation is the process of replacing the old scheme to the new scheme is more complex. Acquisition of the new scheme to be processed consciously and requires a thought process [14]. More complex schemes reconstructed old scheme contains information in the previous scheme [1516], so that the level of complexity of the scheme in the human mind continues to grow over time.

The purpose of this study was to describe the characteristics of the construction of formal-proof based overview of the proof-structure and the conceptual understanding that the students possessed.

\section{Methods}

\subsection{Subject}

Participants of this study were 58 students of $3^{\text {rd }}$ year undergraduate students of developing university in Banten
Province, Indonesia. Reason conducted on these students are (1) The students have taken Numbers Theory course, so they already have the basic related concept of numbers, (2) The students are more easily managed by the researcher to follow the procedures empirically planned, so that the data obtained is a students' actual of reflection thinking.

\subsection{Instruments}

The instrument used in this study is a question adopted from Selden and Selden [17]. The question is "For any positive integer $n$, if $n^{2}$ is a multiple of 3 , then $n$ is a multiple of 3". The instrument used with consideration of: (1) by Selden and Selden [17] in reviewing the mistakes made by students in constructing proofs, (2) the instrument is a simple matter, making it easier to classify the types of proof that are constructed by students, and (3) The instrument has a tools for evaluation of the proof using the Error Proof Evaluation Tools (PEET) which developed by Andrew [18].

\subsection{Data}

In mathematics/statistics education research, some researchers conducted a study that begins in the form of surveys and continued with limited interviews [19-20]. This study adopts similar methods. Giving a proving-question in the beginning, aim to select students who will be the subjects, which further deepened with the interview.

The data used in this article was obtained within 3 phases. In Phase 1 students were asked to write down the proof of proving-question; this stage is expected to provoke students' thinking to construct mathematical proof. The proof written by the students is an image of the students' thinking in constructing proofs. The proof was evaluated using PEET to agglomerate the students' error based overview of the proofstructure and the conceptual understanding that the students possessed.

In Phase 2 students were asked about the knowledge required in constructing such proofs. As for the question on the 2nd stage, namely; 1) Questions about concept image of number multiples of 3,2) Questions about concept definition of number multiples of 3, 3) Questions about reflective thinking on proof validation. The questions which are made on the 2nd stage aim to determine the level of students' understanding of the theorem proved.

Phase 3 is to conduct interviews on the students. Interviews on these students are conducted to deepen the information provided in the phase- 1 and phase-2. Students selected for this interview are based on the results of students grouping using PEET. The selection uses constant comparative method. At least 2 students in each group which are agglomerated in phase-1 will be interviewed. This interview is the main way to get data for qualitative research in the areas of mathematics/statistics education [21].

\section{Results}

Of the 58 students who were given the task of mathematical proofs, there were five students who have written correct proof. Moreover, there are two students that 
are capable in providing written correct proof; but, they are unable in proof. The remaining 51 students are experiencing failure in constructing proofs. The following is the description of the data of the failures experienced by students. The tool used in the evaluation of the proofs was the Error Proof Evaluation Tools (PEET) developed by Andrew [18].

Table 1. Students' error on proof-structure $(\mathrm{S})$ in constructing formal proof

\begin{tabular}{|c|c|c|c|}
\hline No & $\begin{array}{l}\text { Element of Proof } \\
\text { Structure }\end{array}$ & Component Descriptions & $\begin{array}{c}\text { Number of } \\
\text { Students } \\
\text { who made } \\
\text { error }\end{array}$ \\
\hline \multirow[t]{3}{*}{1} & Proof setup & $\begin{array}{l}\text { S1. Introduced variables } \\
\text { without defining them or } \\
\text { performed operations that were } \\
\text { undefined. }\end{array}$ & 8 \\
\hline & & $\begin{array}{l}\text { S1. The approach taken in } \\
\text { proving a statement will not } \\
\text { work. }\end{array}$ & 21 \\
\hline & & $\begin{array}{l}\text { S1. The proof was to be } \\
\text { completed using a specific } \\
\text { method, but this method was } \\
\text { not used. }\end{array}$ & 10 \\
\hline 2 & Assumption & $\begin{array}{l}\text { S2. Made a false assumption } \\
\text { somewhere in the proof. }\end{array}$ & 20 \\
\hline 3 & $\begin{array}{l}\text { Linear/sequential } \\
\text { order }\end{array}$ & $\begin{array}{l}\text { S3. Didn't proceed through the } \\
\text { proof in a linear fashion, and } \\
\text { ideas were not in logical order. }\end{array}$ & 11 \\
\hline \multirow[t]{2}{*}{4} & $\begin{array}{l}\text { Stray details/ } \\
\text { conciseness }\end{array}$ & $\begin{array}{l}\text { S4. The proof contained } \\
\text { extraneous details or steps that } \\
\text { did not really contribute to the } \\
\text { proof. }\end{array}$ & 8 \\
\hline & & $\begin{array}{l}\text { S4. The length of the proof was } \\
\text { unnecessarily long and thus } \\
\text { extremely difficult to follow. }\end{array}$ & 2 \\
\hline 5 & $\begin{array}{l}\text { Neat } \\
\text { presentation }\end{array}$ & $\begin{array}{l}\text { S5. The write-up was illegible } \\
\text { at times, making it diffic ult to } \\
\text { read and/or understand. }\end{array}$ & - \\
\hline 6 & $\begin{array}{l}\text { Technology's } \\
\text { place }\end{array}$ & $\begin{array}{l}\text { S6. Relied too much on } \\
\text { calculator or computer- } \\
\text { generated information in one } \\
\text { step of theproof. }\end{array}$ & - \\
\hline 7 & Proof type & $\begin{array}{l}\text { S7. Needed to show } p \rightarrow q \text { but } \\
\text { did not show directly, or by - } \\
q \rightarrow-p \text {, or by contradiction }\end{array}$ & 8 \\
\hline & & $\begin{array}{l}\text { S7. Only gave an example to } \\
\text { establish the truth of a } \\
\text { mathematicalstatement. }\end{array}$ & 10 \\
\hline 8 & $\begin{array}{l}\text { Correct use of } \\
\text { symbols/notation }\end{array}$ & $\begin{array}{l}\text { S8. Used nonstandard or } \\
\text { confusing notation. }\end{array}$ & - \\
\hline
\end{tabular}

None of the students committed errors in making it difficult to read and/or understand, relying too much on calculator or computer-generated information in one step of the proof, using nonstandard or confusing notation, and relying too much on a picture (corresponding to S5, S6, S8, and U3-2 on Table 1 and 2). This happens because the instrument is a simple proof derivation problem. On the other hand, the three most frequent errors were an error in claiming a statement, the error in making a statement, and one in choosing a proof type. Errors in claims occurred at the beginning of proof by stating $n^{2}=(3 k)^{2}$, with $k$ integer. Mistakes in making a statement made when stating $n^{2}=3 n$. The error in choosing a proof type was by choosing an incorrect method.

Based on PEET results, students' response can be further classified into three categories. First, there are 16 students who wrong in extracting a concept so become wrong in expressing formal proof (corresponding to U4-2 and U5-1on Table 1 and 2). Second, as many as 19 students less likely to complete in deepening the concept, so there is a missing piece of concept (corresponding to S2, S3, U4-1, U5-1 and U5-2on Table 1 and 2). Finally, there are 16 students in group III which committed errors in selecting methods of proof in the initial stage of logic verification (corresponding to S1-2, S2, and S7-1 on Table 1 and 2).

Table 2. Students' error on conceptual-underst anding (U) in constructing formal proof

\begin{tabular}{|c|c|c|c|}
\hline No & $\begin{array}{l}\text { Element of } \\
\text { Mathematical } \\
\text { Concept }\end{array}$ & Component Descriptions & $\begin{array}{c}\text { Number of } \\
\text { Students } \\
\text { who made } \\
\text { error }\end{array}$ \\
\hline 1 & Sufficient details & $\begin{array}{l}\text { U1. Wrote a statement that was } \\
\text { not justified, explained, or } \\
\text { verified. }\end{array}$ & 4 \\
\hline 2 & Clarity & $\begin{array}{l}\text { U2. Wrote a statement or } \\
\text { paragraph that was ambiguous, } \\
\text { confusing, and/or unnecessarily } \\
\text { complex. }\end{array}$ & 3 \\
\hline \multirow[t]{2}{*}{3} & $\begin{array}{l}\text { Pictures in the } \\
\text { proof }\end{array}$ & $\begin{array}{l}\text { U3. Failed to include an } \\
\text { illustrative picture that would } \\
\text { make the proof easier to } \\
\text { understand. }\end{array}$ & 3 \\
\hline & & $\begin{array}{l}\text { U3. Relied too much on a } \\
\text { picture to prove something was } \\
\text { true. }\end{array}$ & - \\
\hline \multirow[t]{2}{*}{4} & $\begin{array}{l}\text { Crucial } \\
\text { step/main idea }\end{array}$ & $\begin{array}{l}\text { U4. Did not sufficiently justif y } \\
\text { a crucial step in the proof. }\end{array}$ & 12 \\
\hline & & $\begin{array}{l}\text { U4. An error caused important } \\
\text { parts of the proof to be left } \\
\text { unaddressed. }\end{array}$ & 10 \\
\hline \multirow[t]{2}{*}{5} & $\begin{array}{l}\text { Correct } \\
\text { implications and } \\
\text { statements }\end{array}$ & $\begin{array}{l}\text { U5. Made a false statement or } \\
\text { incorrect computation in the } \\
\text { proof. }\end{array}$ & 18 \\
\hline & & $\begin{array}{l}\text { U5. Incorrectly claimed that } \\
\text { one statement implied or } \\
\text { equaled another statement. }\end{array}$ & 17 \\
\hline 6 & All cases present & $\begin{array}{l}\text { U6. Included some cases but } \\
\text { not others (which were not } \\
\text { trivial). }\end{array}$ & 1 \\
\hline
\end{tabular}

\section{Proof Structure (S)}

Insufficient concept in formalproof construction

- An error caused important parts of the proof to be left unaddressed.

- False statement or incorrect computation in the proof

Conceptual-

Insufficient concept and Incorrect proof-structure in formal-proof construction

- The proof contained extraneous details or steps that did not really contribute to the proof.

- False statement or incorrect computation in the proof

- Incorrectly claimed that one statement implied or equaled another statement.

Correct Proof Construction

- Correct in Proof-structure

- Correct in Conceptual Understanding

\section{Understanding $(\mathbf{U})$}

Incorrect proof-structure in

formal-proof construction

- The approach taken in proving a statement will not work

- The proof was to be completed using a specific method, but this method was not used.

- False statement or incorrect computation in the proof

Fig. 1. Quadrant model of students formal-proof construction using PEET 
Table 3. Students' responses about knowledge required in constructing the proof

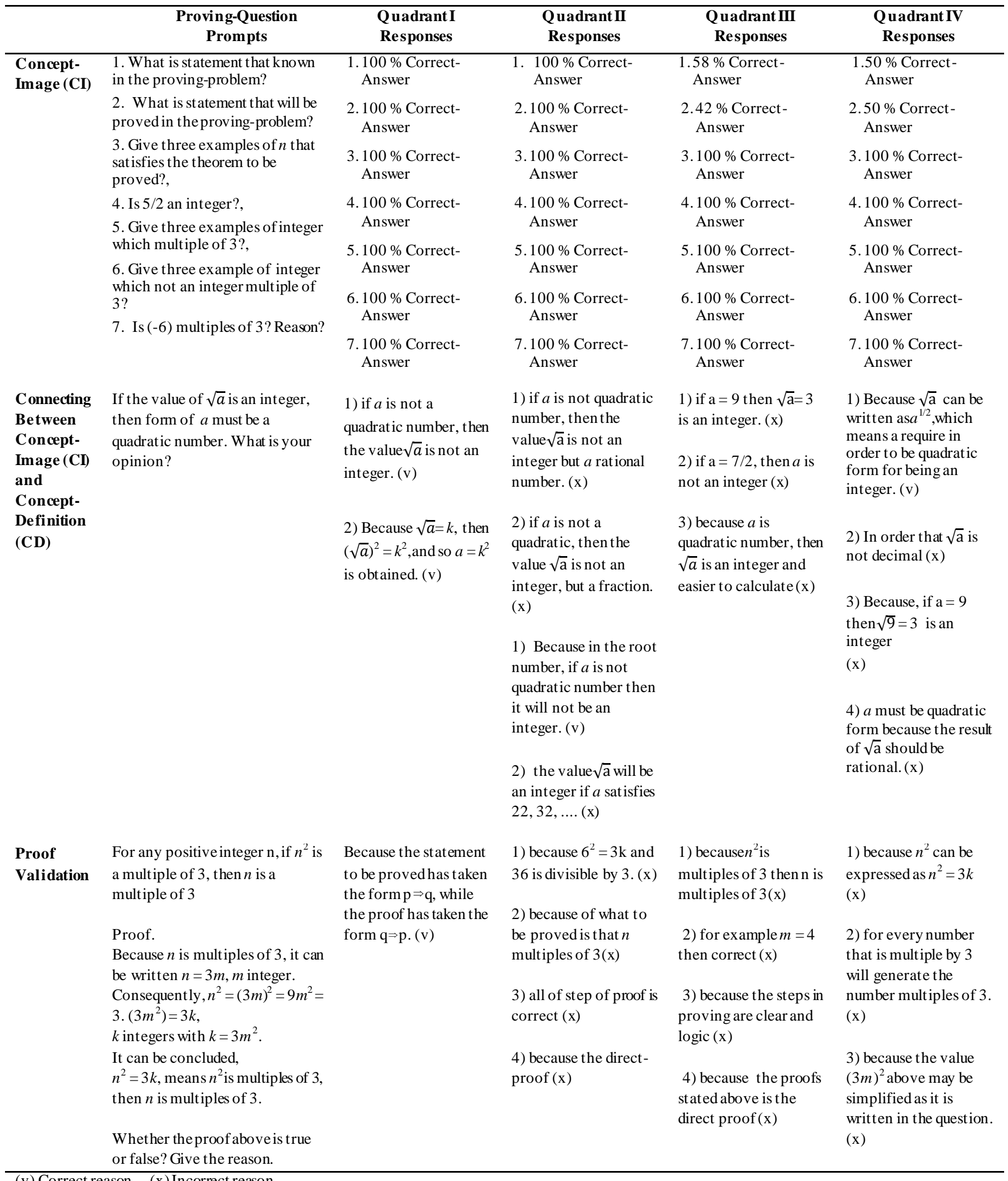

(v) Correct reason (x) Incorrect reason

\section{Discussion}

\subsection{Students' Formal Proof Construction in Quadrant I}

Students' formal proof constructions in this group are the students who are capable of constructing proof-formal accurately. Formal proof construction in Quadrant I were using indirect proof. They prove "If $n$ is not a multiple of 3, then $n^{2}$ is not multiples of $3 "$. It indicates that the students in this quadrant have a structure of logical proof.

The students included in this quadrant find out what is 
known and what is to be proved in the statement which is to be proven. In addition, students in this quadrant are able to give examples of integers that satisfy the statement. Although the examples presented tend to be simple, for instance: 9, 36, and 81 . Most of the students find the value of $n$ that satisfies the statement by starting with $n^{2}$ which are multiples of 3 , then finding the value of $n$. This indicates that the student is able to think logically in understanding this verification statement. Similarly, knowledge related with numbers multiples of 3 , students in this group are able to give examples of numbers that are not multiples of 3 or multiples of 3 . Most of the students in this quadrant exemplify the numbers $2,4,5,7$ and 8 as an example of non-number multiples of 3 . In addition to that, when asked about the numbers -6 , the student replied that -6 is multiples of three, of which approximately 50\% answered because $(-6)=3 \times(-2)$, the rest responded that because (-6) is divisible by 3 . Based on the explanation above, shows that the concept-image about numbers multiples of 3 in this quadrant is classified good.

Corresponding to proving-question about connecting between $\mathrm{CI}$ and $\mathrm{CD}$ on Table 3, all of the answer are correct. From the reasons above, it shows that the students understand the concept of root numbers and the other numbers. This indicates that the student has a good connecting associated with root numbers, quadratic number, and integers.

To proof validation on Table 3 the given proof is an incorrect proof, because the statement to be proved has taken the form $\mathrm{p} \Rightarrow \mathrm{q}$, while the proof has taken the form $\mathrm{q} \Rightarrow \mathrm{p}$. All students in this quadrant stated that the proofs are incorrect because it has a different truth value. The validation process is done by the students has been proceeding well. This is due to the concept of non-equivalency between $\mathrm{p} \Rightarrow \mathrm{q}$ and $\mathrm{q} \Rightarrow \mathrm{p}$ owned by the students, as well as the focus of the validation done by the students tend to be in the process of understanding the proof-structure. Therefore, the reflection with validation as is done by the students in this quadrant is a reflection of understanding of structure.

\subsection{Students'Formal Proof Construction in Quadrant II}

Students in this quadrant are those who experienced U4.2 and U5.1. The errors are caused by an important part of the proof which is not intended, so a statement becomes incorrect or wrong in the calculation operation. The error is related to the incompleteness of the students in understanding concepts. If $n$ is not multiple of 3, then it has two cases, that is 1 or 2 as remainder. The students in this quadrant only write proving for a case.

The students included in this quadrant find out what is known and what is to be proved in the statement which is to be proven. In addition, students in this quadrant are able to give examples of integers that satisfy the statement. Although the examples presented tend to be simple, for instance: 9, 36, and 81 . Most of the students find the value of $n$ that satisfies the statement by starting with $n^{2}$ which are multiples of 3 , then finding the value of $n$. This indicates that the student is able to think logically in understanding this verification statement. Similarly, knowledge related with numbers multiples of 3 , students in this group are able to give examples of numbers that are not multiples of 3 or multiples of 3 . Although most of the students in this quadrant exemplify the numbers 2,4 and 8 as an example-a number that is not multiplies of 3 . In addition, when asked about the numbers -6 , the student replied that -6 is multiples of 3 , where around $65 \%$ answered with a reason because $(-6)=3 \times(-2)$, the rest responded with a reason because (-6) is divisible by 3 . Based on the above, it indicates that the student's concept-image of multiples of 3 in this quadrant is good.

Corresponding to proving-question about connecting between $\mathrm{CI}$ and $\mathrm{CD}$ on Table 3, there are only 1 of 4 answers is correct. It indicates that the students have lack in understanding the concept of a root numbers and the other numbers. Moreover, this indicates that the student has a poor connecting associated with root numbers, quadratic number, and integers.

Now we focus our attention on discussion to proof validation on Table 3 . The validation process which is done by the students does not proceed well. This is due to the concept of non-equivalency between $\mathrm{p} \Rightarrow \mathrm{q}$ and $\mathrm{q} \Rightarrow \mathrm{p}$ is not understood by students. Focus of the validation done by the students tends to be in the algebraic process. Therefore, the reflection with validation as is done by the students in this quadrant is a procedural reflection.

Here are excerpts of the interview on the Student-4's formal proof construction included in Quadrant II.

(1) $\mathrm{Q}$ [Researcher]: $n$ is not multiples of 3 , what are they?

(2) D [Student-4]: $4,3 k+1$

(3) Q: Anything else?

(4) D: $6 k+1$

(5) Q: Is there something else ... .What about 5?

(6) D: Not multiples of 3, It is a remainder.

(7) Q: What are of the remainder?

(8) D: The remainder is 1

(9) Q: Anything else

(10) D: 2

(11) Q: would it be 3?

(12) D: No..., because it is the same of multiples of 3 . This means there is something else, $3 n+2$

The students who belong to this group are indicated that they do not have the necessary related concepts. In line (10), Student- 4 was aware that if $n$ is not multiple of 3, then have two cases that is 1 or 2 as remainder. It shows that Student- 4 didn't do reflective thinking during constructing the proof. Therefore, during interview and when they were asked to recall the neces sary concepts, students in this group were able to recall and recognize their shortcomings in constructing proofs.

\subsection{Students' Formal Proof Construction in Quadrant III}

Students in this group are students who experienced errors on S4, U5.1, and U5.2. The proofs contain some wrong concept, making an incorrect statement in the calculation or wrong in claiming a statement. Such errors tend to occur because students do not understand the concepts needed in the proof, resulting in error of the computational procedure. Examples in this study, the students assume that the multiples of 3 can be written as $n=3 n$, which implies that $1=3$. This is 
confirmed by the data that only $58 \%$ of the students in this quadrant know what is known in the statement to be proved and only $42 \%$ know what is to be proved (corresponding to proof validation on Table 3 ).

Students included in this quadrant were able to provide examples of integers that satisfy statement. The examples tend to be simple, such as number 9,36 , and 81 which are three numbers that are multiples of 3 . Most students find the value of $n$ that satisfies the statement begin with the search for integer $n$ which is multiples of 3, then look for the value of the corresponding $n^{2}$. This indicates that the students have not been able to think logically in understanding this verification statement. Similarly, knowledge related with numbers multiples of 3, students in this group are able to give examples of numbers that are not multiples of 3 or multiples of 3 . In addition, when asked about the numbers (-6), the student replied that $(-6)$ is multiples of three, of which approximately $50 \%$ answered because $(-6)=3 \times(-2)$, the rest responded that because (-6) is divisible by 3 . Corresponding to conceptimage prompt on Table 3, it shows that the students' conceptimage about multiples of 3 in this quadrant is enough.

Corresponding to proving-question about connecting between $\mathrm{CI}$ and $\mathrm{CD}$ on Table 3, all of the reasons are incorrect. It indicates that the students have lack in understanding the concept of a root numbers and the other numbers. This also indicates that the student has a poor connection associated with root numbers, quadratic number, and integers.

Corresponds to proof validation on Table 3 , the validation process which is done by the students does not proceed well. This is due to the concept of non-equivalency between $p \Rightarrow q$ and $q \Rightarrow p$ is not understood by students. Focus of the validation done by the students tends to be in the process algebra. Therefore, the reflection with validation as is done by the students in this quadrant is a procedural reflection.

Students who belong to this group had less prior knowledge in the proving-question and made less reflection on the necessary concepts. When they were asked to recall the necessary concepts, students in this group could not realize their shortcomings in constructing proofs. An example of the formal-proof derivation is provided in Appendix A. Here are excerpts of the interview on Student-5.

(13) Q [Researcher]: You have written $3 n=3 . n$, and then $3 . n=3^{2} . n^{2}$, why?

(14) R [Student-5]: It's squared

(15) Q: Why is it squared?

(16) R: to get $n^{2}$ multiples of 3

\subsection{Students' Formal Proof Construction in Quadrant IV}

Students' formal proof construction in this group is students who experienced the error S1.2 and U5.2, which they chose the wrong approach and made a mistake in claiming a statement. Such errors reflected error in logical deduction. This is confirmed by the data that only $50 \%$ of the students in this quadrant know what is known in the statement to be, and only $50 \%$ know what is to be proved (corresponding to proof validation on Table 3).

Students included in this quadrant were able to provide examples of integers that satisfy the statement. Examples that is proposed tend to be simple, for making a quadratic number 9,36 , and 81 which are three numbers that are multiples of 3 . Most students find the value of $n$ that satisfies the statement begins with the search for integer $n$ which is multiples of 3 , and then look for the value of the corresponding $n^{2}$. This indicates that the student has not been able to think logically in understanding this verification statement. Similarly, knowledge related with numbers multiples of 3, students in this group are able to give examples of numbers that are not multiples of 3 or multiples of 3 . In addition, when asked about the numbers $(-6)$, the student replied that $(-6)$ is multiples of 3 , of which $50 \%$ answered because $(-6)=3 \times(-2)$, the rest responded that because (-6) is divisible by 3 . Corresponding to concept-image prompt on Table 3, it shows that the students' concept-image about multiples of 3 in this quadrant is enough.

Corresponding to proving-question about connecting between $\mathrm{CI}$ and $\mathrm{CD}$ on Table 3, there are only 1 of 4 answers is correct. It indicates that the students have lack in understanding the concept of a root numbers and the other numbers. This indicates that the student has a poor connecting associated with root numbers, quadratic number, and integers.

Corresponds to proof validation on Table 3 , the validation process which is done by the students does not proceed well. This is due to the concept of non-equivalency between $p \Rightarrow q$ and $q \Rightarrow p$ is not understood by students. Focus of the validation done by the students tends to be in the algebraic process. Therefore, the reflection with validation as is done by the students in this quadrant is a procedural reflection.

The students used incorrect approaches or incorrect methods in constructing the proof. It is caused the students have a prior knowledge which not fit with the proof structure. Thus, it all begins with error in choosing method of proving that resulted an error in claiming a statement.

Instead of choosing the correct method of students who belong to this group indicated that they used mathematicalinduction method due to have been working on similar problems that use mathematical induction. An example of the formal-proof derivation is provided in Appendix B. Here are some excerpts of the interview Student-1.

(17) Q [Researcher]: Why did you used this method?

(18) F [Student-1]: Previously... I've seen from the examples in the book explained by Mr. Anwar (Student-1's Lecturer-red).

(19) Q: What is it?

(20) F: But, It was different ... .Question from Mr. Anwar, "Prove $n^{2}+n$ is multiples of 2 for $n$ is natural numbers". In this problem, it is known if $n^{2}$ is multiples of 3 then $n$ is multiples of 3 .

(21) Q: Why did you starts from $n$ is multiples of 3 ?

(22) F: That, sir. I want to take an example from the note, I'm confused....

Here are excerpts of the interview on Student-2.

(23) Q [Researcher]: Why did you used this method?

(24) N [Student-2]: Yesterday I suddenly think of using an induction, the one that is like the mathematical induction, first, it's $n=1$, and there are $n^{2}$ and $\mathrm{n}$, so I inserted $\mathrm{n}=1$. So it's true for $n=1$ and also for $n=k$. 
From the definition of $n^{2}$.

Here are excerpts of the interview on the Student-3.

(25) Q [Researcher]: Why did you use mathematical induction method?

(26) J [Student-3]: Usually induction is used. It is like the problems multiples of 3

(27) Q: Have you answered similar questions with mathematical induction?

(28) J: Yes....

In these three examples, students' prior knowledge determined the mathematical proof that they chose the engage in success of the mathematical proof construction that is made.

\subsection{Suggestion in Learning Each Quadrant}

Based on the description about the mathematical formal proofs stated by the previous researchers [5, 18], this article has proposed a model that adopts the structure-proof and concepts understanding in constructing proofs. Formal proof construction can be grouped into four quadrants. Each quadrant has a characteristic that differentiates it from other quadrants. This model could give consideration in how to help students who are in quadrant II, III, and IV to be able to construct a formal proof as in Quadrant I.

Among attempts to improve students' proof comprehension to constructing a formal-proof, one can distinguish two broad approaches: (a) changing the presentation of the proof and (b) changing the way a student engages with it [22]. The aim of changing the presentation is to make easier in understanding proof-structure. Leron [23] suggested that instead of a standard linear presentation-proceeding from hypothesis to conclusion in a unidirectional manner-one might present structured proofs. A structured proof is arranged in levels, with the main ideas and approach given at the top level and subsequent levels giving details and justifications of each of the steps in the preceding levels.

When the presentation is changed, explanations are must provide by the instructor. The explanations can help students who construct incorrect-proof to understand how constructing correct-proof. In terms of Mejía-Ramos et al.'s [24] framework, a structured proof is designed to facilitate understanding of higher-level ideas and identifying modular structure, though it does so at the expense of separating some claims from their supporting data and warrants. These changes are reflected in empirical research on the efficacy of structured proofs. Fuller et al. [25] found that, compared to those who read a traditional proof, students who read structured proofs were more successful at summarizing the key ideas of the proof. This way can help students who in Quadrant-II and Quadrant-IV.

Other way to do this is to provide worked examples. Worked examples usually provide students with example problems and worked-out solution steps for final answers [26]. A commentary is added to the solution steps in order to describe the underlying reasons why the step is selected. A solution included in a worked example demonstrates a step by step solving the problem. It is sugges ted that a useful worked example should show an effective procedure as applied by experts [27].
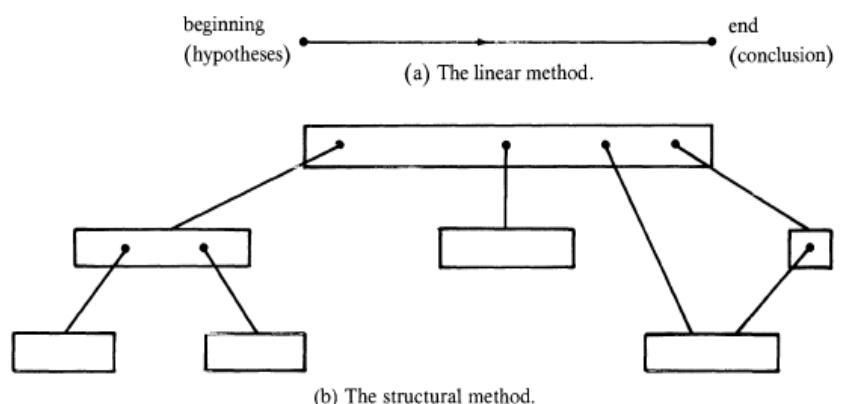

Fig. 2. The two methods of presentation (Taken from [24])

\begin{tabular}{|c|c|}
\hline \multicolumn{2}{|c|}{ Proof Structure (S) } \\
\hline $\begin{array}{l}\text { Quadrant II } \\
\text { Insufficient concept in formal- } \\
\text { proof construction } \\
\text { - Rich CI } \\
\text { - Poor connection } \\
\text { between CI and CD } \\
\text { - Correct Proof-structure } \\
\text { - Reflective commentary } \\
\text { focuses on procedural }\end{array}$ & $\begin{array}{l}\text { Quadrant I } \\
\text { Correct Proof Construction } \\
\text { - Rich CI } \\
\text { - Good connection } \\
\text { between CI and CD } \\
\text { - reflective commentary } \\
\text { focuses on } \\
\text { understanding of the } \\
\text { structure }\end{array}$ \\
\hline $\begin{array}{l}\text { Suggested Learning } \\
\text { - Structuring } \\
\text { Mathematical Proof } \\
\text { - Self-explanation }\end{array}$ & $\begin{array}{l}\text { Suggested Learning } \\
\bullet \text { Direct Instruction/ } \\
\text { Learning }\end{array}$ \\
\hline & $\begin{array}{r}\text { Conceptual- } \\
\text { Understanding }(\mathrm{U})\end{array}$ \\
\hline $\begin{array}{l}\text { Quadrant III } \\
\text { Insufficient concept and } \\
\text { Incorrect proof-structure in } \\
\text { formal-proof construction } \\
\text { - Enough CI } \\
\text { - Poor connection } \\
\text { between CI and CD } \\
\text { - Unable to appear proof- } \\
\text { structure } \\
\text { - Reflective commentary } \\
\text { focuses on procedural }\end{array}$ & $\begin{array}{l}\text { Quadrant IV } \\
\text { Incorrect proof-structure in } \\
\text { formal-proof construction } \\
\text { - Enough CI } \\
\text { - Poor connection } \\
\text { between CI and CD } \\
\text { - Incorrect Proof- } \\
\text { structure } \\
\text { - Reflective } \\
\text { commentary focuses } \\
\text { on the procedural }\end{array}$ \\
\hline $\begin{array}{l}\text { Suggested Learning } \\
\text { - Worked-Examples } \\
\text { - Self-explanation }\end{array}$ & $\begin{array}{l}\text { Suggested Learning } \\
\text { - Structuring } \\
\text { Mathematical Proof } \\
\text { - Self-explanation }\end{array}$ \\
\hline
\end{tabular}

Fig. 3. Characteristics of each-quadrant of students' formal-proof construction

Research has shown that studying worked examples in contrast to conventional problem solving is an effective way to enhance understanding why solution steps are effective, how the operators should be applied and the rationale 
underlying solution procedures [28]. This way can help students who in Quadrant-III.

The second broad approach to improving proof comprehension is to change a student's engagement with a proof. One way to do this is to provide self-explanation training [22]. Studies also indicate that self-explanation training might be helpful in mathematics [29]. Renkl [30] argued that self-explanations are often faulty or otherwise inadequate and developed an approach in which the learner does as much self-explanation as possible but also has access to additional instructional explanations. Nevertheless, empirical results on self-explanation effects are compelling. They indicate that self-explanation training can enhance students' comprehension of mathematical material and of texts at the undergraduate level in other subjects. These ways can help students in constructing formal-proof. Thus, the model can be summarized in Fig. 3 .

\section{Conclusion}

Characteristics of students' formal proof construction can be built using PEET developed by Andrew [18]. Characteristics formal proof construction can be grouped into four quadrants, i.e. Quadrant I, II, III, and IV. Characteristic of Quadrant I, namely: rich CI, good connection between CI and $\mathrm{CD}$, reflective commentary focuses on understanding the proof structure. Characteristics of Quadrant II, namely: rich CI, Proof-structure has emerged, good connection between CI and $\mathrm{CD}$, reflective commentary focuses on the procedural. Characteristics of Quadrant III, namely: CI is enough, poor connection between $\mathrm{CI}$ and $\mathrm{CD}$, reflective commentary focuses on procedural. While the characteristics of Quadrant IV, namely: enough CI, wrong proof-structure, and reflective commentary focuses on the procedural.

Therefore, each quadrant has a characteristic that differentiates it from other quadrants. This model could give consideration in how to help students who are in quadrant II, III, and IV to be able to construct a formal proof as in quadrant I.

\section{References}

1. D.O. Tall, et al. The Cognitive Developmentof Proof. In In Hanna, G. and De Villiers, M. (Eds). ICMI 19: Proof Proving Mathematics Education (2011) 13-49.

2. D.O. Tall. Differing Modes of Proof and Belief in Mathematics International Conference on Mathematics: Understanding P roving and Proving to Understand (2002) 91-107.

3. R,C. Moore. Making the transition to formal proof. Educ. St ud. Math. 27 (1994) 249-266.

4. J. Knapp. Learning to prove in order to prove to learn. [online] : Retrieved from URL: http://mathpost.asu.edu/ sjgm/issues/2005_spring/ SJGM_knapp.pdf.

5. A. Selden, K. McKee and J. Selden. Affect, behavioural schemas and the proving process. Int. J. Math. Educ.Sci. Tech. 41 (2010) 199-215

6. L. Sowder and G. Harel. Case studies of mathematics majors' proof understanding, production, and appreciation. Can. J. Sci. Math. Tech. Educ. 3(2) (2003) 251-267.

7. M.M.F. Pinto and D.O. Tall. Studentconstructions of formal theo ry: giving and extracting meaning. In O. Zaslavsky (Ed.), Proceedings of the $23^{\text {rd }}$ Conference of the International Group for the Psychology of Mathematics Education Vol. 4 (1999) 65-73.

8. K. Weber. Traditional instruction in advanced mathematics co urses: A case study of one professor's lectures and proofs in an introductory real analysis course. J. Math. Behav. 23 (2004) 115-133.

9. L. Alcock and K. Weber. Semantic and syntactic proof productions. Educ. Stud. Math. 56 (2004) 209-234.

10. J.C. Smith. A Framework for Characterizing the Transition to Advanced Mathematical Thinking. Proceedings of the $26^{\text {th }}$ Annual Meeting of the North America Chapter of the International Group for the Psychology of Mathematics Education Vol. 1 (2004) 163-171

11. J. Sweller. Human Cognitive Architecture. In J. M. Spector, M. D. Merril, J. J. G. van Merriënboer, \& M.P. Driscoll (Eds.), Handbo ok of Research on Educational Communications and Technology pp 369-381. New York: LawrenceErlbaum Associates. 2008.

12. J. Sweller, P. Ayres, and S. Kalyuga. Cognitive Load Theory: Explorations in the Learning Sciences, Instructional Systems and Performance Technologies. London: Springer. 2011.

13. J. Sweller. Cognitive Load Theory. In J. P. Mestre \& B. H. Ross (Eds.), The Psychology of Learning and Cognition in Education (2011) 37-74.

14. J. Sweller and S. Sweller. Natural information processing systems. Evol. Psych. 4, (2006) 434-458.

15. F. Paas, A. Renkl and J. Sweller. Cognitive Load Theory and Instuctional Design: RecentDevelopment. Educ. Psych. 38 (1) (2003) 1-4.

16. F. Paas, T. van Gog, and J. Sweller. Cognitive load theory: New conceptualizations, specifications, and integrated research perspectives. Educ. Psych. Rev. 22(2) (2010) 115-121.

17. A. Selden and J. Selden. Validations of Proofs Considered as Texts: Can Undergraduates Tell Whether an Argument Proves a Theorem? J. Res. Math. Educ. 34 (1) (2003) 4-36.

18. L. Andrew. Creating a Proof Error Evaluation Tool for Use in the Grading of Student-Generated "Proofs". PRIMUS: Problems, Resources, and Issues in Mathematics Undergraduate Studies 19(5) (2009) 447-462.

19. Amir and J. Williams. Cultural Influences on Children's Probabilistic Thinking. J. Math. Behav. 18(10) (1999) 85-107.

20. J.M. Watson and R. Callingham. Statistical literacy: A complex hierarchical construct. Stat. Educ. Res. J. 2(2) (2003)3-46.

21. S. Sharma. Qualitative Methods in Statistics Education Research: Methodological Problems And Possible Solutions. Proceedings of the Eighth International Conference on Teaching Statistics (2010)

22. M. Hodds, L. Alcock and M. Inglis. Self-Explanation Training Improves Proof Comprehension. J. Res in Math Educ. 45(1) (2014) 62-101

23. U. Leron. Structuring mathematical proofs. Americ. Math. Month. 90(3) (1983) 174-184

24. J.P. Mejía-Ramos, E. Fuller, K. Weber, K. Rhoads, and A. Sam k off. An assessment model for proof comprehension in undergraduate mathematics. Educ. Stud.Math. 79(1) (2012) 3-18

25. E. Fuller, J.P. Mejía-Ramos, K. Weber, A. Samkoff, K. Rhoads, D. Doongaji, and K. Lew. Comprehending Leron's structured proofs. In S. Brown, S. Larsen, K. Marrongelle, \& M. Oehrtman (Eds.), Proce edings of the 15th Annual Conference on Research in Undergraduate Mathematics Education (2011) 84-102.

26. J.Y. Hsiao, C.L. Hung, Y.F. Lan, and Y.C. Jeng. Integrating Worked Examples Into Problem Posing in a Web-based Learning Environtment. TOJET: Turk. Online J. Educ. Tech. 12 (2) (2013) 166-176

27. R.K. Atkinson, S.J. Derry, A. Renkl, and D. Worthan. Learning from examples: Instructional principles from the worked examples re se a rch. Rev. Educ. Res. 70(2) (2000) 181-214.

28. K. Durkin. The self-explanation effect when learning mathematics: A 
meta-analysis. Paper presented at the Society for Research on Educational Effectiveness Spring 2011 Conference on Building and Education Science: Investigating Mechanisms, Washington, DC.

29. J. Sweller. Instructional design consequences of an analogy between evolution bynatural selection and human cognitive architecture. Instruct. Sci. 32(1-2) (2004) 9-31.

30. Renkl. Worked-out examples: Instructional explanations support learning by self-explanations. Leam. Instruct. 12(5)(2002)529-556.

\section{$\underline{\text { Appendix A }}$}

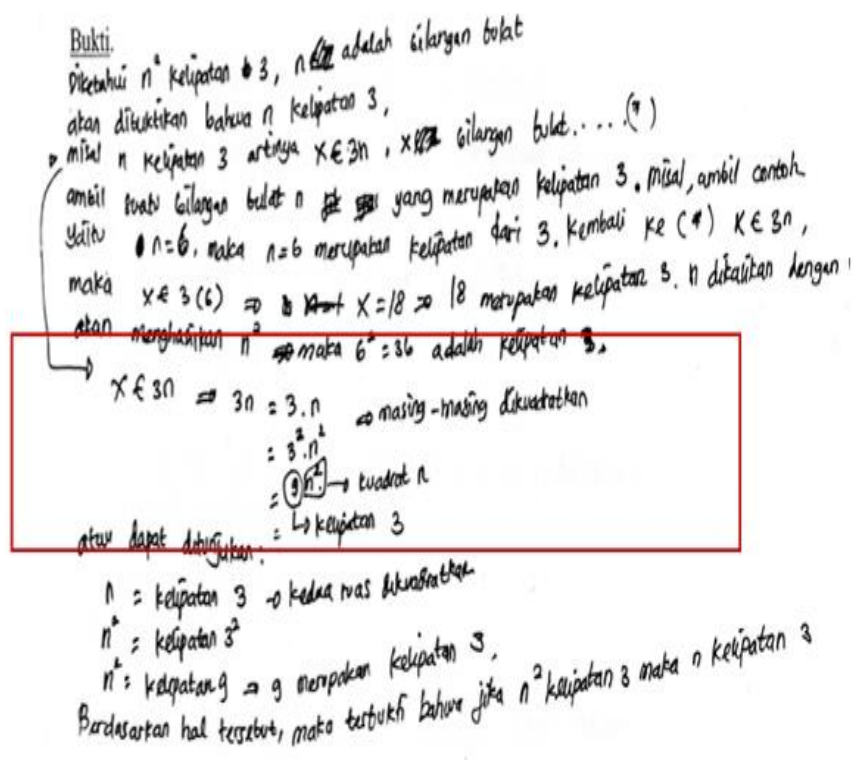

\section{Translation in English.}

The hypotheses: $n^{2}$ is multiple of $3, n$ integer. We will prove that $n$ is multiples of 3 . Suppose that $n$ is multiple of 3, its mean $x \in 3 n, x$ integer......*)

Let an integer which multiple of 3, for example $n=6$, then $n=6$ is multiple of 3 . Refer to $\left(^{*}\right)$, then $x=3(6) \rightarrow x=18,18$ is multiple of 3. $n$ multiplies by $n$ yields $n^{2}$, and then $6^{2}=36$ is multiple of 3 .

$x \in 3 n \rightarrow 3 n=3 . n$, we quadrate for each side, yields

$$
=3^{2} \cdot n^{2}
$$

Or can be displayed.

$n=$ multiplies of 3 , we quadrate for each side, yields $n^{2}$ multiples of $3^{2}$

$$
n^{2} \text { multiples of } 9 ; 9 \text { is multiplies of } 3
$$

According that its proved that if $n^{2}$ is multiple of 3 , then $n$ multiple of 3 .

\section{Appendix B}

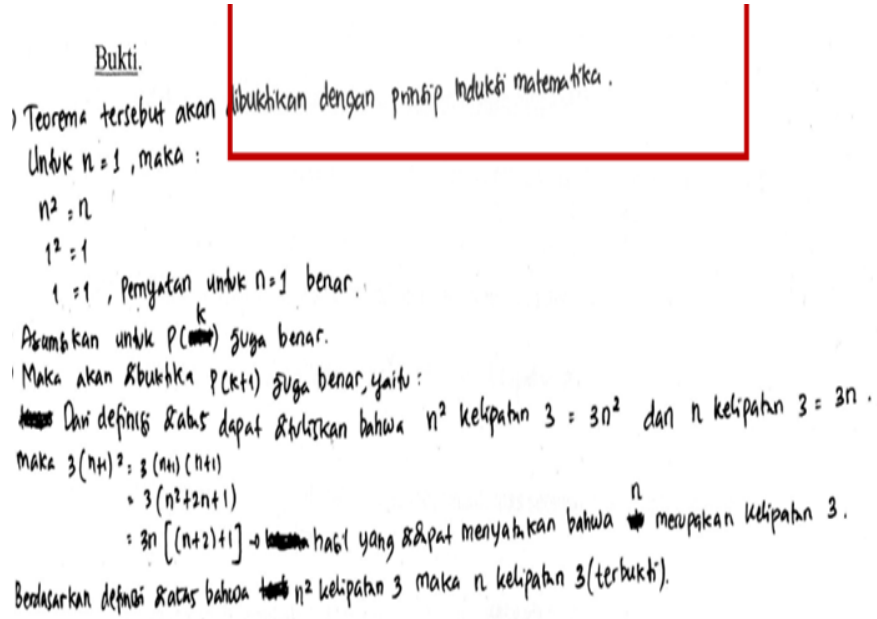

\section{Translation in English.}

The theorem will be proven using mathematical induction.

For $n=1$, then

$$
\begin{aligned}
& n^{2}=n \\
& 1^{2}=1 \\
& 1=1, \text { that is true for } n=1
\end{aligned}
$$

Assumed for $\mathrm{P}(\mathrm{k})$ is true, then we will prove $\mathrm{P}(\mathrm{k}+1)$ is true.

From the definition: $n^{2}$ multiple of $3=3 n^{2}$ and $n$ multiple of 3

$=3 n$. Thus, $3(n+1)^{2}=3(n+1)(n+1)$

$$
\begin{aligned}
& =3\left(n^{2}+2 n+1\right) \\
& =3 n[(n+2)+1]
\end{aligned}
$$

Its indicate that $n$ is multiple of 3 .

According the definition, we claimed that $n^{2}$ multiplies of 3 then $\mathrm{n}$ multiplies of 3 (Proved). 